Vol. 38(1), pp. 1-14, June 2019

ISSN 1821-536X (print)

ISSN 2619-8789 (electronic)
Tanzania Journal of Engineering and Technology

Copyright @ 2019 College of Engineering and

Technology, University of Dar es Salaam

Full Length Research Paper

\title{
The Comparative Analysis of the Performances of Four and Six Pole Pairs Permanent Magnet Synchronous Generator
}

\author{
R.A. Msuya ${ }^{1 *}$, R.R.M. Kainkwa ${ }^{1}$ and M.I. Mgwatu ${ }^{2}$ \\ ${ }^{1}$ Departrment of Physics, College of Natural and Applied Sciences, University of Dar es \\ Salaam, P.O. Box 35065, Dar es Salaam, Tanzania. \\ ${ }^{2}$ Departrment of Mechanical and Industrial Engineering, College of Engineering and \\ Technology, University of Dar es Salaam, P.O. Box 35131, Dar es Salaam, Tanzania. \\ *Corresponding author: msuya@yahoo.com
}

\begin{abstract}
Wind power applications using multi-poles permanent magnet generators have become very attractive especially in small ratings. Low-speed multi-pole PM generators are maintenance-free and may be used in different climate conditions. Most of the low speed wind turbine generators presented is permanent magnet machines, which have advantages of high efficiency and reliability since there is no need of external excitation and conductor losses are removed from the rotor. From the study two types of PM AC generator are designed with 6 pole pairs and the other one with 4 pole pairs. These generators were designed and analysed using Maxwell software. The results were compared for the best performance determination. The 6 poles generator was found to have good power output with less Total Harmonic Distortion (THD) and high efficiency of over 92\% that could be achieved at low wind speed of $2 \mathrm{~m} / \mathrm{s}$.
\end{abstract}

Keywords: Comparisons, Performance, Permanent Magnet Wind Generator, Pole Pairs.

\section{INTRODUCTION}

The use of permanent magnet (PM) generators in wind turbines system is a common trend. Such type of generators has good efficiency, reliability, low speed and also small weight and need minimum servicing (Aleksander and Oleg, 2012). The outer diameter of this PM generator is relatively big due to large number of magnets that form pole pairs of the generator, which can be in any number depending on the size of the generator. There are some different constructions of permanent magnet generators that are used in wind turbines.
For wind power applications in particular, multi-pole permanent magnet generators have become very attractive especially in small ratings (Ocak at el., 2012). Permanent magnet synchronous generators (PMSG) are one of the best solutions for small-scale wind power plants. Low-speed multi-pole PM generators are maintenance-free and may be used in different climatic conditions. It is possible to combine PM wind generators for hybrid technologies such as wind-diesel, wind photovoltaic, etc. To convert wind power into electricity, many types of generator concepts have been proposed and used. Most of the low speed wind turbine generators presented is permanent magnet machines. These have advantages of high 
efficiency and reliability since there is no need of external excitation and conductor losses are removed from the rotor (Ocak at el., 2012). In this work the two permanent magnet generators with inner rotor were analysed based on number of pole pairs where the generator with 4 pole pairs and 6 pole pairs were designed and their performance was compared (Figure 1).
Generator with inner rotor suits very well for small wind turbines. This kind of design makes the construction of a turbine more convenient due to simple installation of the wind rotor directly to the generator surface. On the other hand, the construction with inner stator blocks the heat transfer from the stator winding.

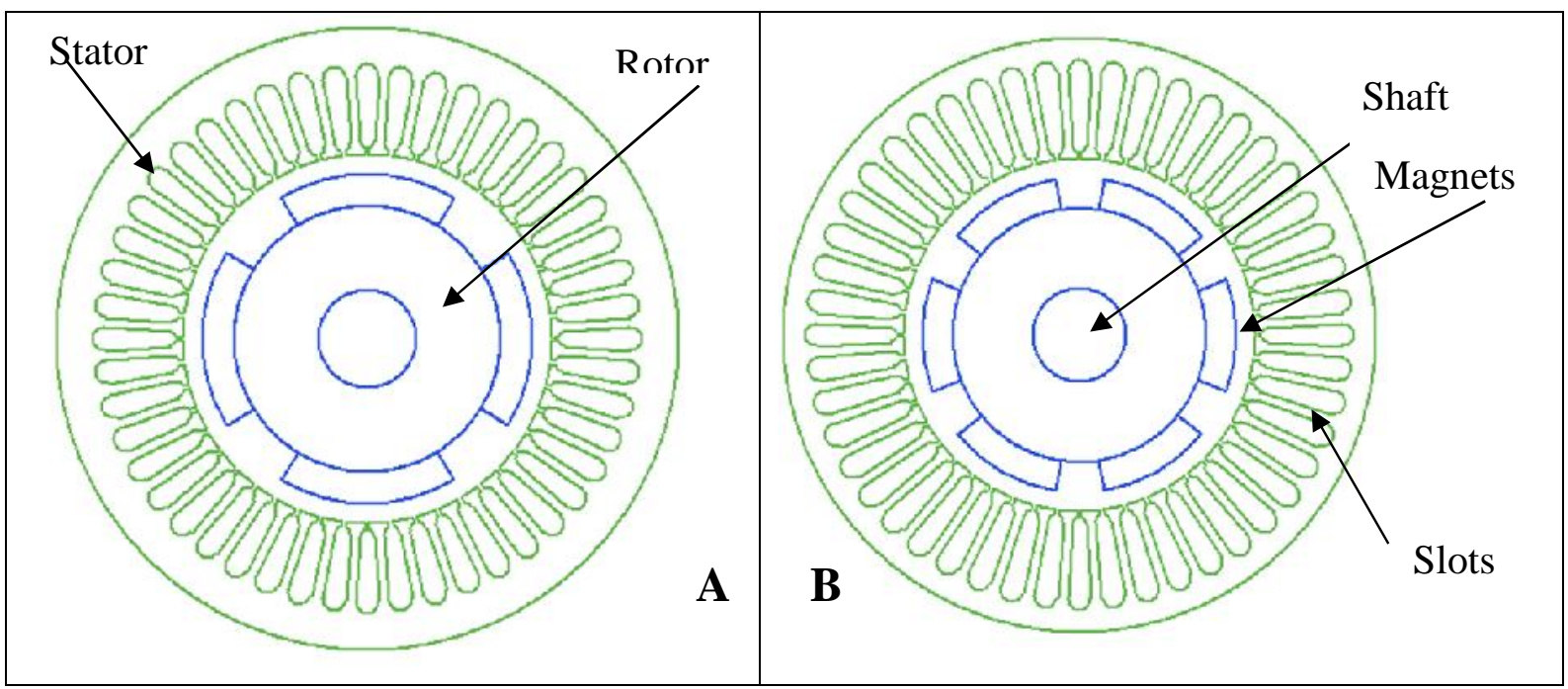

Figure 1: Four Pole (A) and Six Pole (B) Generators

Table 1: Technical specification of the two generators

\begin{tabular}{|c|c|c|}
\hline S/No. & Parameter characteristics of wind turbine PM AC generator & Values and Unit \\
\hline 1 & Power Output & $1000 \mathrm{~W}$ \\
\hline 2 & Rated speed (max) & $200(\mathrm{rpm})$ \\
\hline 3 & Rated power & $1 \mathrm{~kW}$ \\
\hline 4 & Max power & $1.5 \mathrm{~kW}$ \\
\hline 5 & Output voltage & $12-64 \mathrm{~V}$ \\
\hline 6 & Startup speed & $50(\mathrm{rpm})$ \\
\hline 7 & Work speed & $50-200(\mathrm{rpm})$ \\
\hline 8 & Security speed & $350(\mathrm{rpm})$ \\
\hline
\end{tabular}

\section{METHODS AND MATERIALS}

In the first step of study, the main dimensions of the generator were determined. The stack length, air-gap length, slots and number of poles were optimised for design of an inner rotor permanent magnet generator. Stack length has significant influence on the main parameters of a generator as magnetic flux, current density and losses. Varying the number of magnetic poles between six and four causes the difference in generator performance that have been compared for determining the optimal efficiency of the machine.

The PM machines are characterized by airgap flux between the stator and rotor as shown in Figure 2. The structure uses one 
cylindrical stator form and a cylindrical rotor both having the same inner and outer diameters which defines the active part of the machine where the electromechanical conversion takes place. These types of machines are particularly suitable for low speed, high power stand-alone wind turbine system for small scale power applications. The structures of the PM machine show the wide flat permanent magnets and the stator iron with the benefit of increasing the total air gap surface. As the air gap becomes wide, the flux density is reduced and hence necessitate larger surface of magnet. The air gap is supposed to be as small as possible so as to maximize the air gap flux density, to minimize the flux leakage and produce reluctance value, because the air gap constitutes the largest part of the machine performance (Cao et al., 2010). The locally manufactured PM generators in Tanzania are developed with magnets which are chosen to be wide and flat, so as to decrease the amount of inactive area in the air gap and thereby reduce the generator size (Figure 3). The PM generator designed and manufactured in Tanzania is a delta connected and has eight poles pairs in order to achieve good induction and high efficiency.

The equivalent circuit of PM synchronous generator is shown in Figure 4. The circuit included the values $I_{g}, R_{g}$ and $L_{g}$, which are the generated current, internal resistance of the generator and inductance of the generator, respectively. $E$ is the emf across the generator and $V$ is the voltage across the load resistance $R_{L}$.

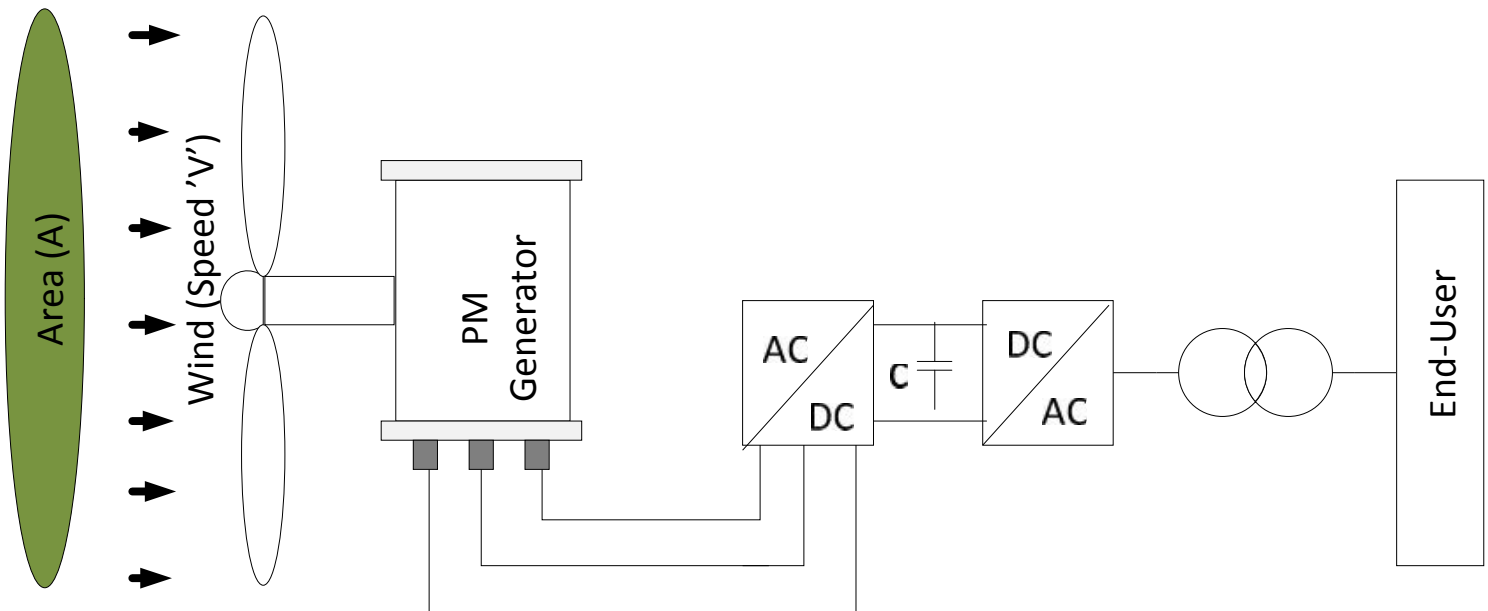

Wind Turbine System

Figure 2: Wind turbine system 


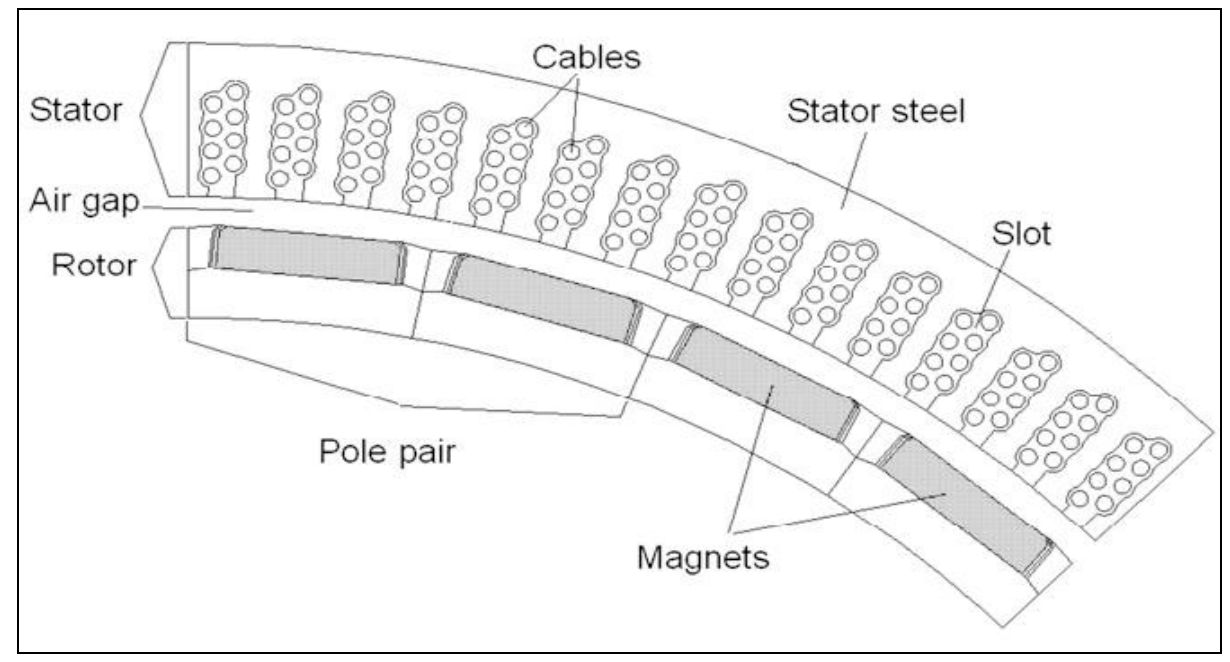

Figure 3: Internal parts of the PM Generator

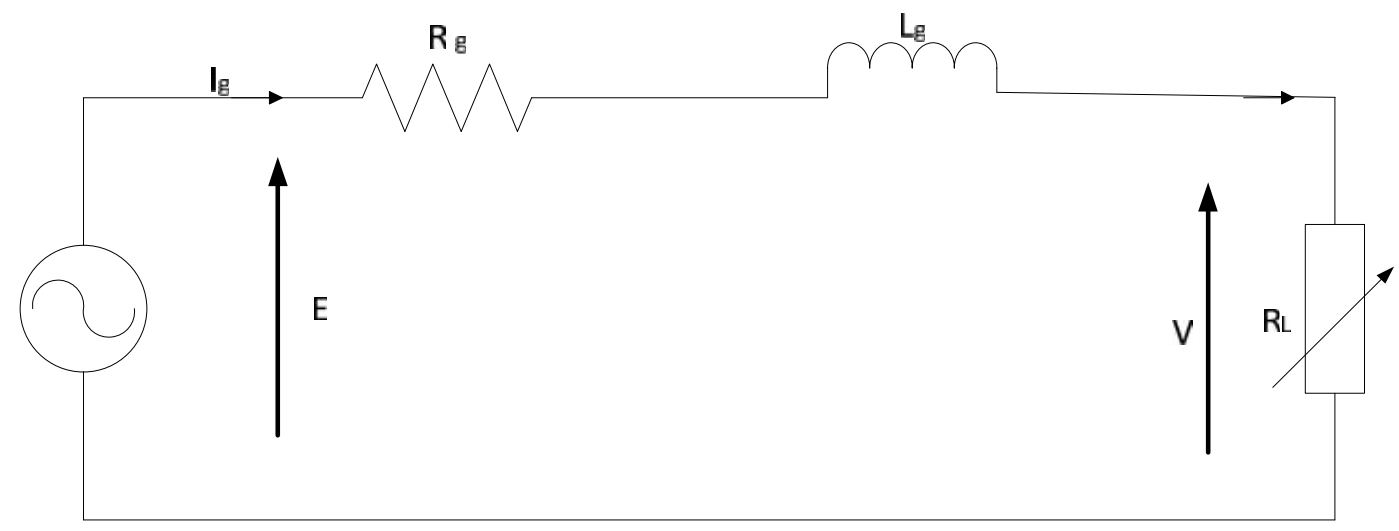

Figure 4: Equivalent circuit of the PM generators used in used in the laboratory test

The power output of PM synchronous generator depends on the input mechanical power, which may also be obtained from rotor of a wind turbine, an engine or prime mover. The prime mover exert the mechanical power to the rotor of a generator, where the output power will be electrial power from the generator. The higher the angular speed, the greater the electrial power convertion is realised (Abeywardena et al., 2011). The electromagnetic losses consist of resistive losses in the copper conductor, hysteresis losses, eddy current losses and excess (or anomalous) losses. The mechanical losses are dominated by couplings and bearings. A general power flow diagram shown in Figure 5 indicates that the power loss is dominated by two major components namely the mechanical losses and the electrical losses. The loss due to friction is about $1 \%$ for same conditions (DongChoon and Ahmed, 2008). For light load conditions, the mechanical losses increase and system efficiency is deteriorated.

Mechanical losses are difficult to estimate in many systems, but it should be noted that anything that moves in most cases creates some friction at a given level. The most mechanical loss of the wind turbine generator is associated with bearings. The effect of bearings can be minimized when the best or high-quality industrial bearing are used in the system. The other generator loss is associated by copper and iron losses, which depend on the current and flux level. In the normal conditions the 
copper losses take place in the coils of the generator.

Electric current suffers from a kind of friction, where by the friction is proportional to the resistance of the copper wire carrying current. This resistance causes energy to be lost through heating up the wire. This loss can be reduced by using a thicker wire, but this will make the generator heavier and more expensive. It should be also noted that the resistance of a copper wire increases with temperature increases. Copper losses in terms of heat increase with the square of the current flowing in the conductor. Too much heat increase can burn off the insulator and the wires which might results in short out or even destroy the machine. Therefore, the cooling system is important to be considered during designing the generator. The iron loss can be decreased by reducing the flux level for low load resistance. Iron based cores are mostly used in generator designing and manufacturing, which by no way it will have iron losses. However, iron cores helps direct magnet flux more efficiently. The iron loss can be explained in eddy current and permeability loss. The permeability loss happens when the direction of flux in the coil changes. The magnetic fluxes flowing in one direction inside the coil for one magnetic pole, but when it comes to the next magnetic pole, the fluxes direction reverse. Eddy current loss occur when an electron gets lost inside the core material.

The power converter losses are dependent on the current and switching frequency, which is a lower portion of the total loss and is difficult to control. However, power output is associated with many losses stray losses, friction loses core losses and copper losses as machine works. In some small stand-alone wind turbine generators are mostly made to produce the alternating current (AC power). For this type of the machine the rectifier will be required to change the $\mathrm{AC}$ to direct current (DC power) so that it can be possible to store the power in a battery. Typically, we use this power to charge a battery where a rectifier will be required. In this case there will be a voltage drop across the rectifier which will in turn lose energy in the form of heat. Therefore, it is important to consider this losses during the output power calculation $\left(P_{o}\right)$.

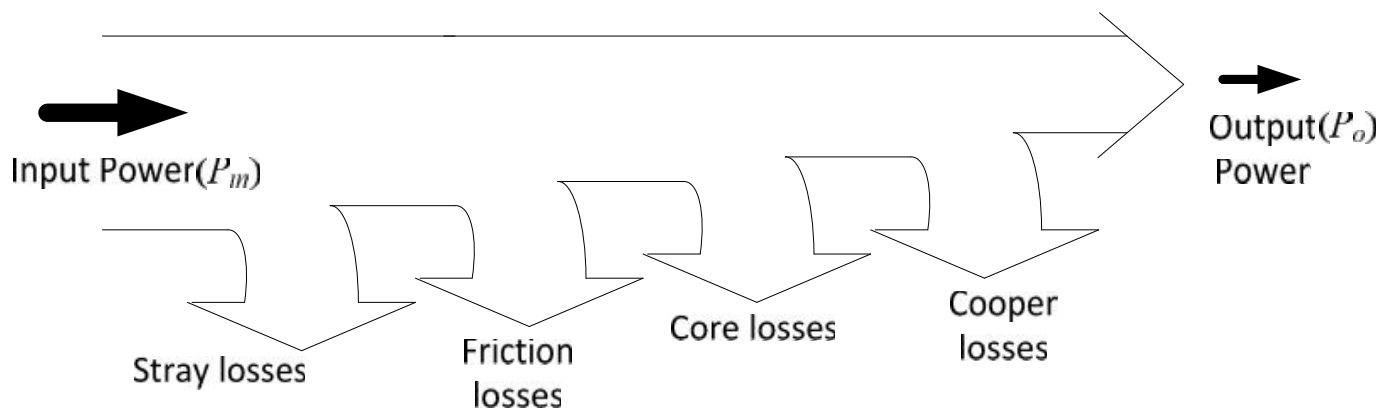

Figure 5: PM generator output power and associated losses

The power output $P$ can be defined as the product of current $I$ flowing in the circuit and voltage $V$ across the the three phase generator loop circuit. For delta connection, the output power can be expressed by equation (1) (Cistelecan et al., 2010; Tcheslavski, 2008).
$P_{D}=\sqrt{3} V_{o} I_{o} \cos \theta$

where $V_{0}$ is phase voltage, $I_{0}$ is phase current and $\theta$ is power factor angle.

For the star connection, equation (2) is used (Cistelecan et al., 2010; Tcheslavski, 2008). 
$P_{S}=\sqrt{3} V_{o} I_{L} \cos \theta$

where $\mathrm{I}_{\mathrm{L}}$ is Line current

The reactive power $P_{R}$ for both connection of the AC synchronous generator, whether delta or star, can be expressed by equation (3) (Tcheslavski, 2008).

$$
P_{R}=\sqrt{3} V_{o} I_{L} \sin \theta
$$

The generator reactive power is the background energy movement in an alternating current generating system from magnetic fied, where the energy is stored in the field in each ac circle change. The virtual magnetic field developed by the flowing current in the generator is assumed to absorb the reactive power, whereas virtuel electric field that store energy generate the said reactive power (Chapadel et al., 2011) while apparent power $P_{A}$ can then be written as shown by equation (4).

$$
P_{A}=\sqrt{3} V_{o} I_{L}
$$

Generally, the mechanical input power $\left(\mathrm{P}_{\text {in }}\right)$ to the wind turbine generator can be from the wind mechanical power which can be expressed by equation (5) (Amirat et al., 2007):

$P_{\text {in }}=\frac{1}{2} \rho \pi R^{2} v^{3} C_{P}$

where $\rho$ is the air density $\left(\mathrm{kg} / \mathrm{m}^{3}\right), R$ is the blade radius $(\mathrm{m})$ of the wind turbine, $\mathrm{v}$ is the wind speed $(\mathrm{m} / \mathrm{s})$, and $C_{p}$ is the power coefficient of the wind turbine, which is a ratio of the electricity produced by wind turbine to the total energy available in the wind.

The mechanical input power to the wind turbine generator $P_{\text {in }}$ can also be defined in the rotational speed and torque (Zhang et $a l ., 2011)$ as shown in equation (6).

$$
P_{i n}=T_{e} \omega
$$

where $T_{e}$ is electromagnetic torque, $\omega$ is mechanical angular velocity.

Many researchers have discussed several procedures and methods of finding the efficiency of the wind turbine generators and general performance of wind generator. The major consideration is the input mechanical power to the generator with the output electrical power and loss conditions of generator that can be determined from rotating speed of the machine (Tamura and Muyeen, 2012). They suggested that the efficient of the generator can be determined using the ratio of total output power $P_{o}$ to the total input power $P_{i n}$. Tamura and Muyeen (2012) gave also a flow diagram to show step by step on how to determine the efficiency of the whole turbine performance in the field. The flow chart suggested that the mechanical losses and stray load loss cannot be expressed in a generator equivalent circuit, but they can be deducted from the wind generator output. Wind speed was taken as mechanical input power to the system, where power produced were multiplied by the gearbox efficiency, but this should be for nondirect driven systems. The mechanical loss and stray loss were then deducted from the wind turbine output power. The generator input power is equivalent with the turbine output power.

The following steps are to calculate the copper loss and iron loss from the equivalent circuit and calculate the generator stray loss and mechanical loss. By removing the losses, the net electrical output power of the generator is then realized as consequently the entire output power of the turbine system. The external characteristic of the generator performance is considered as most important as it gives the relationship between the terminal voltage against output current and the resistive load (Guo et al., 2008). From the phase output equivalent electrical circuit of the 
generator shown in Figure 6, the external

(7) (Guo et al. 2008).

characteristic can be derived from equation

$V=\sqrt{E^{2}-I^{2}\left(\omega L_{g} \cos \theta-R_{g} \sin \theta\right)^{2}}-I_{g}\left(\omega L_{g} \sin \theta-R_{g} \cos \theta\right)$

where $V$ is the terminal voltage and $E$ is the back Emf. $I_{g}$ is the the load current, while $\omega$ is equivalent to $2 \pi f$, which is

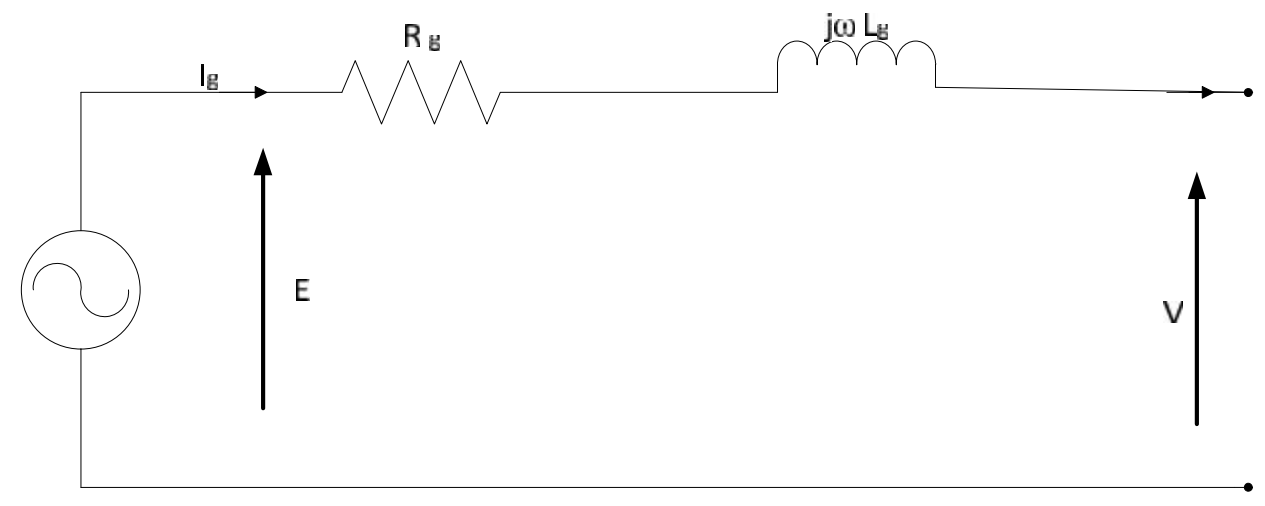

angular frequency of the electricity, $L_{g}$ is while $\theta$ is the power factor of the load. inductance and $R_{g}$ is the phase resistance,

Figure 6: PM AC generator phase equivalent circuit

With reference to equation (7), the external characteristics of the PM synchronous generator can be achieved when the load resistance is varied. During the variation of the load resistance the external behaviour of the current and voltage can be realised, which determines the generator characteristics. If the equivalent electrical circuit is considered, the electrical output power, the mechanical input power, input mechanical torque, and efficiency of the PM generator can be calculated per phase as shown by equation (8) (Guo et al., 2008).

$$
P_{o}=3 V I_{g} \cos \theta
$$

Hence the total mechanical input power can then be computed using equation (9).

$P_{i n}=P_{o}+P_{c u}+P_{F e}+P_{m e c}$

where $P_{c u}$ is copper loss, $P_{F e}$ is iron loss and $P_{m e c}$ is mechanical losses.

Therefore, the efficiency can be evaluated and expressed as shown by equation (10).

$\eta=\frac{P_{o}}{P_{i n}}$

Maxwell 2D software was adopted in modeling the PM AC synchronous generator. The Ansoft Cooperation Rotational Machine Expert (RMxprt) software was used for initial designing of the PM AC generator, because it has ability to get an easy and fast response in a convenient form and the output data can be easily adopted by the other Ansoft like Maxwell 2D Design. This programme also can-do optimization of the parameters. The analysis was done by the Maxwell 2D software after the design imported from the Maxwell RMxprt software. Together Maxwell2D and RMxprt used to create a customized machine design for higher efficiency and lower cost machines. RMxprt can automatically set up the complete Maxwell project (2-D) including geometry, materials, boundary conditions including the appropriate symmetries and excitations with coupling circuit topology 
for electromagnetic transient analysis (Ansoft Maxwell Field Simulator v12, 2008). The model development and simulation were based on the Maxwell's Equations and the finite element method (FEM), which is a numerical method that allows solving equations based on magneto-static problems with nonlinear B$\mathrm{H}$ relationships.

Figure 7 shows the slot design of PM generator and the proposed size, which normally depends on the size of the generator and the proposed power output. The newly designed PM AC Synchronous machines were tested in different rotational speed, starting from $50 \mathrm{rpm}$ to $1300 \mathrm{rpm}$, which is equivalent to wind speed of $0.3 \mathrm{~m} / \mathrm{s}$ to $7.8 \mathrm{~m} / \mathrm{s}$ as converted through Equation 11 (Kolar et al., 2012):

$$
\text { Speed }(\text { Rpm })=\frac{60000 \times \text { Speed }\left(\mathrm{ms}^{-1}\right)}{\pi \times \text { Diameter }(\mathrm{mm})(\text { Rotor })}
$$

Complete machine design structures of the generators (Figure 1) were run with the Maxwell software with reference speed $350 \mathrm{rpm}$. The rotational speed was varied at the interval of $50 \mathrm{rpm}$ (i.e. 50, 100, 150, $200 \ldots 1300 \mathrm{rpm})$ where at each different rotational speed, the values of all parameters were recorded and the behaviour and performance of the machines were examined. The computation of all other parameters will be based on the reference speed, which was selected to be $350 \mathrm{rpm}$, and maximum speed $1000 \mathrm{rpm}$, which is equivalent to 2.1 $\mathrm{m} / \mathrm{s}$ of wind speed to $6.0 \mathrm{~m} / \mathrm{s}$. The friction loss was assigned by the software to 27.4 watts, operation temperature was selected to be $50{ }^{\circ} \mathrm{C}$ which is high temperature for most of African countries and the infinite bus was selected from the software to be a fundamental analysis on the generator system, which is a useful representation for energy converter interfaced to a utility through a transmission. Generally, the infinite bus is a modelled ideal voltage source, i.e., a voltage source of constant amplitude, frequency and phase for external circuit of a generator output.

The parameters were recorded while running the new designed generators at different angular speed at the state of Full Load Condition, whereas at the state of No Load, the parameters were computed by Maxwell software where the parameters was computed by the system. When all the required parameters were inserted correctly with some adjustment of some of them, the model was simulated. The values from the state of No Load obtained as a result of the interaction between the magnetic field and the coil winding of the generator. The design was repeated three times while varying the number of pole pairs. The first design used 6 pole pairs, while second design involved 4 pole pairs with the purpose of having the improved efficiency. 


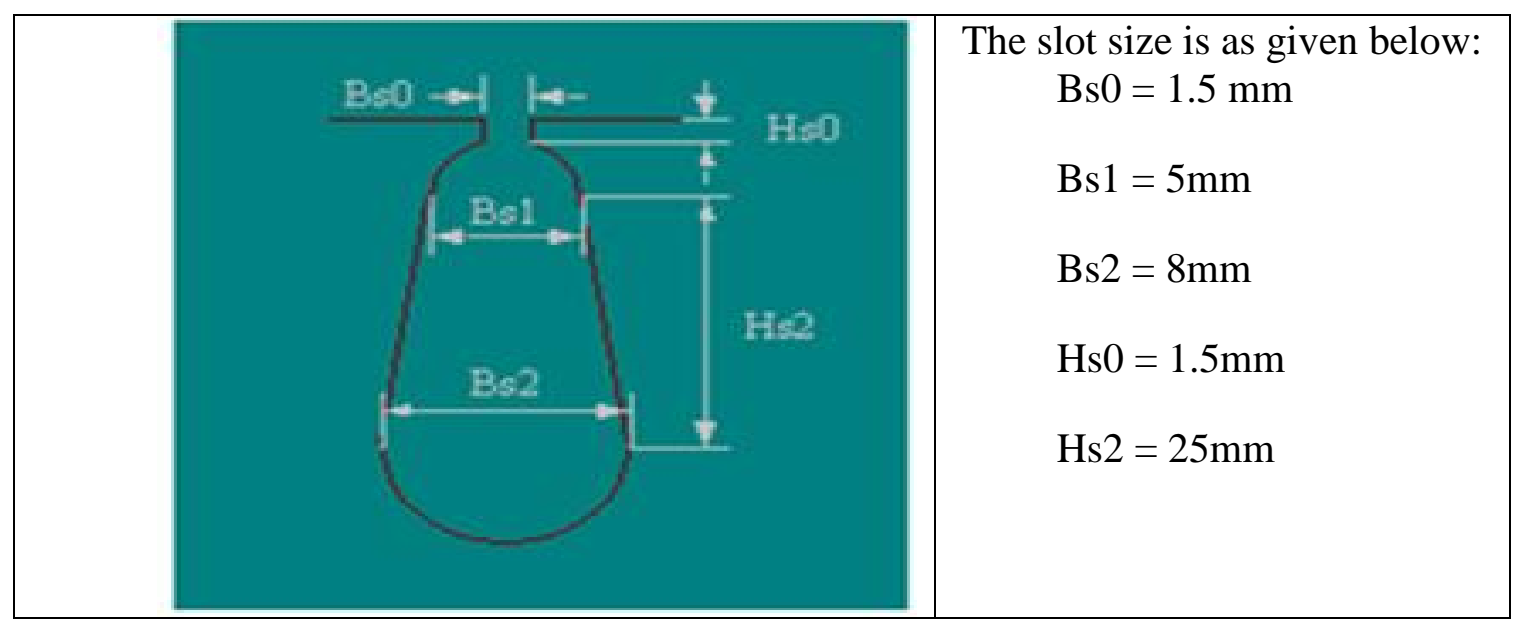

Figure 7: The Local Generator Slot Size

\section{RESULTS AND DISCUSSION}

The PM AC generator model was developed and then simulated in the Maxwell 2D and RMxprt software. The general data used for modelling of 6- and 4- pole pairs PM AC generators are shown in Table 2.

Table 2: The general data for two designed PM AC generators

PM Synchronous Generator Design (Ref speed $350 \mathrm{rpm}$, Rated speed 1000rpm)

\begin{tabular}{|l|c|c|}
\hline \multirow{2}{*}{ General Data } & 6-Poles & 4-Poles \\
\cline { 2 - 3 } & & \\
\hline $\begin{array}{l}\text { Rated output power } \\
(\mathrm{kW})\end{array}$ & 1 & 1 \\
\hline Rated power factor & 1 & 1 \\
\hline Power factor type & Inductive & Inductive \\
\hline Rated voltage (V) & 48 & 48 \\
\hline Number of poles & 6 & 4 \\
\hline Frequency (Hz) & 50 & 33.3 \\
\hline Frictional loss (W) & 34.3 & 34.3 \\
\hline Windage loss (W) & 0 & 0 \\
\hline Rotor position & Inner & Inner \\
\hline $\begin{array}{l}\text { Operating temperature } \\
\left({ }^{\circ} \mathrm{C}\right)\end{array}$ & 50 & 50 \\
\hline Domain & Time & Time \\
\hline
\end{tabular}

Generally, the results show that some of the variables were varying according to the speed change and some were affected much by the change in the pole pairs of the designed machines. Some of these parameters include power loss during the operational like friction loss, copper loss and iron core loss, torque and shortcircuiting current. Figure 8 shows the loss associated with the pole's changes in the machine, whereby all the loss types are drown in the same graph. For detailed observation it can be seen that the big loss is contributed by the friction, while others contribute a small amount. Moreover, the graph trend is the same for all generators. At the low speed the friction loss is high and decreases with speed increase. The friction loss for both generators is in Copper loss. The loss in 4 pole pair is 60 Watt which is high as compared to 6 pole pairs, which have 40 Watts loss. The graph shows that that the copper loss is not changing much with speed increase. The same applied to iron core loss which also is not change with speed increases, but affected by pole pairs changing. From these graphs we can conclude that the generator loss is mostly contributed by the mechanical and fictional losses during the machine operation. Figure 8 shows that the total loss is a bit high for 4 pole pairs generator as compared to 6 pole pairs generator, which both shows that the high the speed the lower is the total generator power loss. More comparative results for the two generators are summarised in Table 3. 


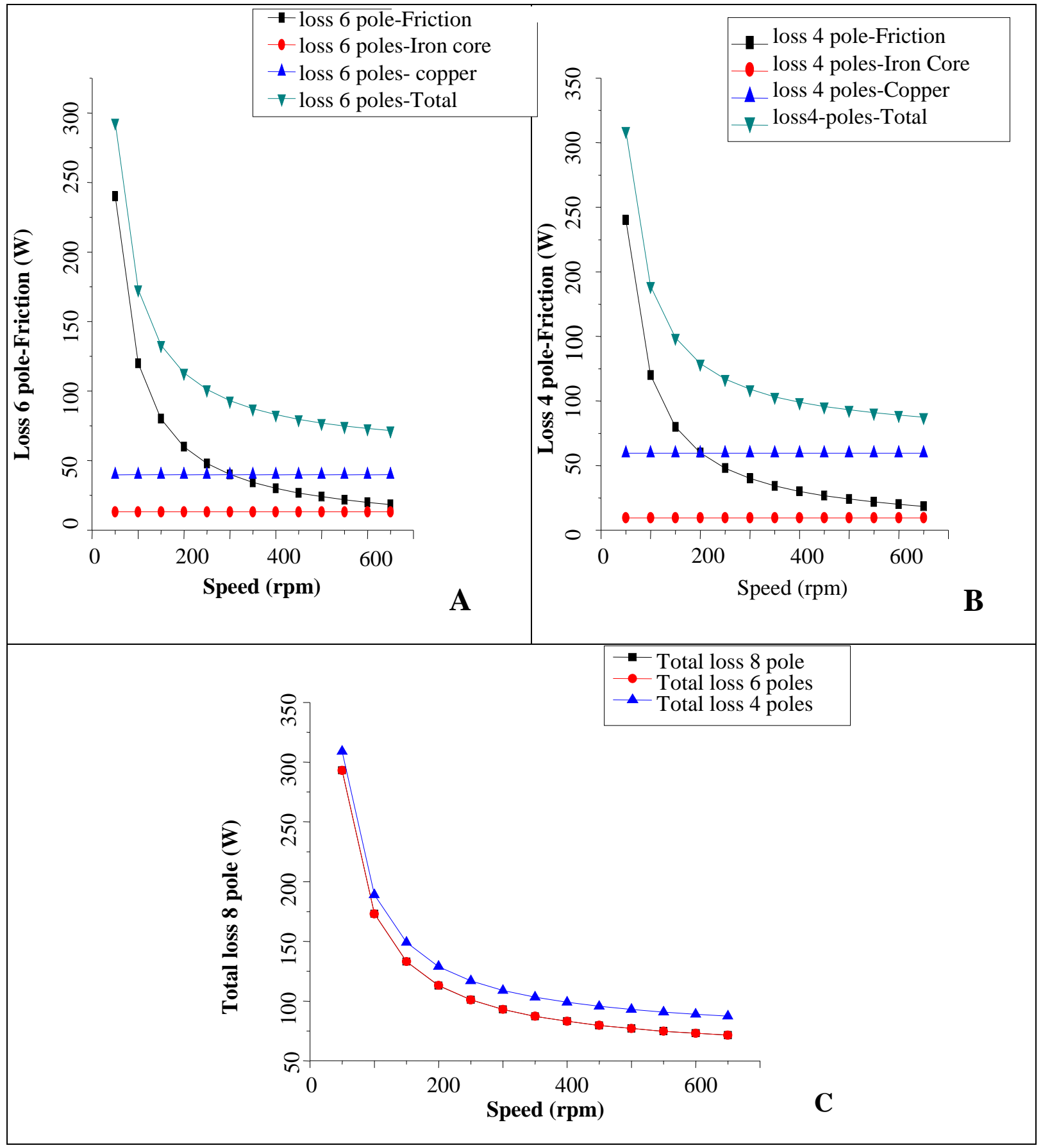

Figure 8: Total loss comparison for 6-pole pairs generator (A), 4-pole pairs generator (B) and all three designed generators $(C)$ 
Table 3: Comparison of output variables for 6-pole and 4-pole PM AC generators

\begin{tabular}{|c|c|c|c|c|}
\hline $\mathbf{S} / \mathbf{N}$ & Variable & 6- pole PM AC generator & 4- pole PM AC generator & Observations \\
\hline 1 & $\begin{array}{l}\text { Moving } \\
\text { torque }\end{array}$ & $\begin{array}{l}\text { Moving torque drops from } \\
\text { zero to }-34.7 \mathrm{NM} \text { and then } \\
\text { rises to }-32 \mathrm{NM} \text { at sinusoidal } \\
\text { pulses. }\end{array}$ & $\begin{array}{l}\text { Moving torque drops from } \\
\text { zero at }-40 \mathrm{NM} \text { and then } \\
\text { rises to }-33.5 \mathrm{NM} \text {, it } \\
\text { dropped again to }-34 \mathrm{NM} \\
\text { at sinusoidal pulses. }\end{array}$ & $\begin{array}{l}\text { Moving torques for both } \\
\text { generators are almost } \\
\text { similar. }\end{array}$ \\
\hline 2 & $\begin{array}{l}\text { Winding } \\
\text { current }\end{array}$ & $\begin{array}{l}\text { The current in the winding of } 6 \\
\text { poles machine raised to } \pm \\
22.8 \mathrm{~A} \text { then drop to } \pm 18 \mathrm{~A} \text { and } \\
\text { continue in a smooth } \\
\text { sinusoidal for } 3 \text { phases } \\
\text { equally. }\end{array}$ & $\begin{array}{l}\text { The } 4 \text { poles machine, the } \\
\text { current raised to } \pm 20.6 \mathrm{~A} \\
\text { and drop to } \pm 14.9 \mathrm{~A} \text { and } \\
\text { continually with smooth } \\
\text { sinusoidal pulses. }\end{array}$ & $\begin{array}{l}\text { Same winding currents } \\
\text { with small differences. } \\
\text { The less the number of } \\
\text { poles to the machine the } \\
\text { less is the winding current. }\end{array}$ \\
\hline 3 & Total loss & $\begin{array}{l}\text { Losses rise to } 1.38 \mathrm{~kW} \text { and } \\
\text { drop to } 0.76 \mathrm{~kW} \text { with time and } \\
\text { then fluctuate between } 0.80 \text { to } \\
0.85 \mathrm{~kW} \text {. }\end{array}$ & $\begin{array}{l}\text { Losses rise to } 1.16 \mathrm{~kW} \text { and } \\
\text { then dropped to } 0.56 \mathrm{~kW} \\
\text { and operate between } 0.56 \\
\text { to } 0.6 \mathrm{~kW} \text {. }\end{array}$ & $\begin{array}{l}\text { The losses for the } 4 \text { poles } \\
\text { machine are generally less } \\
\text { than the losses for } 6 \text { pole } \\
\text { machines. }\end{array}$ \\
\hline 4 & $\begin{array}{l}\text { Air gap } \\
\text { flux } \\
\text { density }\end{array}$ & $\begin{array}{l}\text { Low total harmonic distortion } \\
\text { (THD) of induced voltage } \\
\text { which is } 1.1 \% \text {. The air gap } \\
\text { flux density is } 0.484 \text { Tesla. }\end{array}$ & $\begin{array}{l}\text { High total harmonic } \\
\text { distortion (THD) of } \\
\text { induced voltage which is } \\
1.9 \% \text {. The air gap flux } \\
\text { density for the } 4 \text { poles } \\
\text { machine is } 0.482 \text { Tesla }\end{array}$ & $\begin{array}{l}\text { These distortions result } \\
\text { from the wide space size } \\
\text { between the bar magnet } \\
\text { embedded to the rotor } \\
\text { surface which cause some } \\
\text { flux losses in the air gap. }\end{array}$ \\
\hline 5 & $\begin{array}{l}\text { Cogging } \\
\text { torque }\end{array}$ & $\begin{array}{l}\text { Big cogging torque is } 0.02028 \\
\mathrm{Nm} \text {. }\end{array}$ & $\begin{array}{l}\text { Small cogging torque } \\
\text { which is } 0.00176 \mathrm{Nm}\end{array}$ & $\begin{array}{l}\text { The cogging torque is } \\
\text { directly proportional to the } \\
\text { number of pole pairs of the } \\
\text { machine }\end{array}$ \\
\hline 6 & $\begin{array}{l}\text { Phase } \\
\text { voltage }\end{array}$ & $\begin{array}{l}\text { Induced phase voltage is } \pm 70 \\
\text { Volts. }\end{array}$ & $\begin{array}{l}\text { Induced phase voltage is } \\
\pm 70 \text { Volts. }\end{array}$ & $\begin{array}{l}\text { No distortions observed in } \\
\text { the phase voltage in the } \\
\text { curve of phase voltage } \\
\text { against electric degree. } \\
\text { The values of the induced } \\
\text { phase voltage are the same } \\
\text { for both generators. }\end{array}$ \\
\hline 7 & $\begin{array}{l}\text { Phase and } \\
\text { line } \\
\text { current }\end{array}$ & $\begin{array}{l}\text { Low phase current distortions } \\
\text { have been observed. }\end{array}$ & 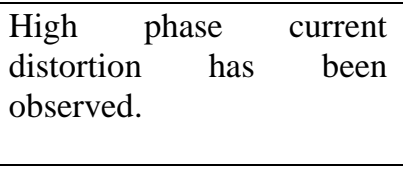 & $\begin{array}{l}\text { Distortions are due to wide } \\
\text { space between the } \\
\text { magnetic bar and cogging } \\
\text { torque. }\end{array}$ \\
\hline
\end{tabular}

The number of turns in the stator winding is directly related to the air gap flux density when the stator diameter and length are kept in a good proportion. It can be shown that the induced voltage in the windings $V \propto B, L, R, N$, where $V$ is induced voltage, $B$ is flux density in Tesla, $L$ is the length of the air gap, $R$ is the radius of the air gap, and $N$ is the number of conductors in the field. Since $R$ and $L$ are kept constant, the number of turns' variation will influence the variations in the air gap flux density for constant induced voltage in the machine.
To reduce cogging torque, it is important to consider the equation (12) (Dosiek and Pillay, 2007). It can be noted that the cogging torque interact with magnetic flux at the air gap and the stator teeth which creates the periodic reluctance variations which causing the cogging torque to be periodic. Thus, the periodic cogging torque can be expressed by the relation (Dosiek and Pillay, 2007):

$$
T_{c o g}=\sum_{k=1}^{\infty} T_{m k} \sin (m k \theta)
$$


where $m$ is the least common multiple of the number of stator slots $(N s)$ and the number of poles $(N p), \mathrm{k}$ is an integer while $T_{m k}$ is a Fourier coefficient.

It is seen that the cogging torque has $m$ periods per revolution of the rotor and is directly proportional to the number of slots and poles; hence the reduction of cogging torque will be under the control of the rotor position, air gap magnetic flux and rotor speed.

Generally, the fundamental standard of stator current waveforms can be expressed (Sittisrijan and Ruangsinchaiwanich, 2013) as shown by equation (13).

$$
I_{m h}=\sum_{n=1,2, \ldots}^{\alpha} I_{n} \sin \left(n \omega_{e} t+\theta_{n}\right)
$$

where $I_{n}$ is a harmonic order of the peak current and $\theta_{n}$ is initial phase angle of the harmonic order phase current.
The efficiency of the designed generators was also computed from the data generated by the software during the variation of the rotational speed from 50 to $650 \mathrm{rpm}$ for each machine. The output efficiency of the 6 poles and with 4 poles are presented in the Figure 9, where it can be observed that general trends is similar but the efficiency of the 6-pole pair machine is higher than that of the 4 pole pairs machine. At 50 $\mathrm{rpm}$, the efficiency of 4 pole pair machine is $76.4 \%$ while the 6 poles machine was $77.4 \%$ and at the $650 \mathrm{rpm}$ the efficiency of 4 pole pars machine was $92.0 \%$ while the 6 pole pairs generator was $93.3 \%$. With these values we can conclude that the 6 poles machine is better than the 4 poles machine. The general output power for both generators (Figure 10) was $1 \mathrm{~kW}$ obtained at the speed from $400 \mathrm{rpm}$ and above.

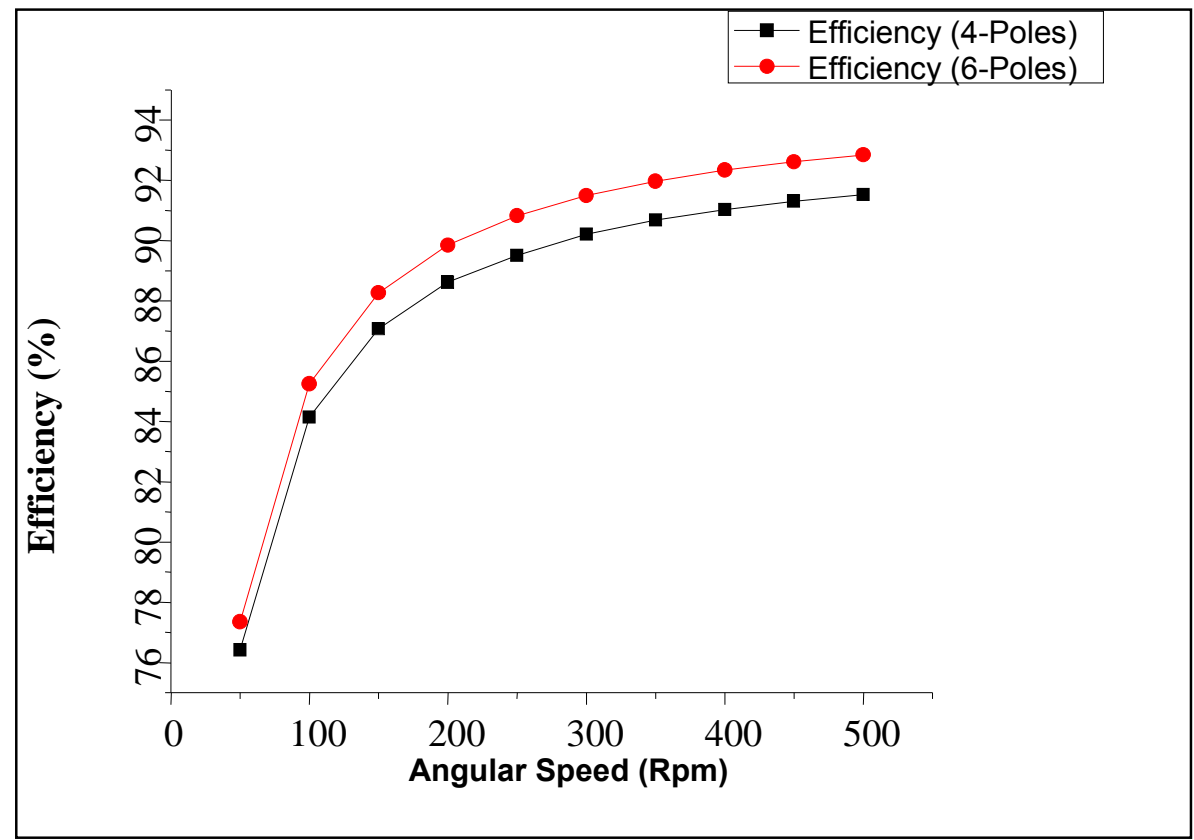

Figure 9: The output efficiency for 6 and 4 pole pairs PMG 


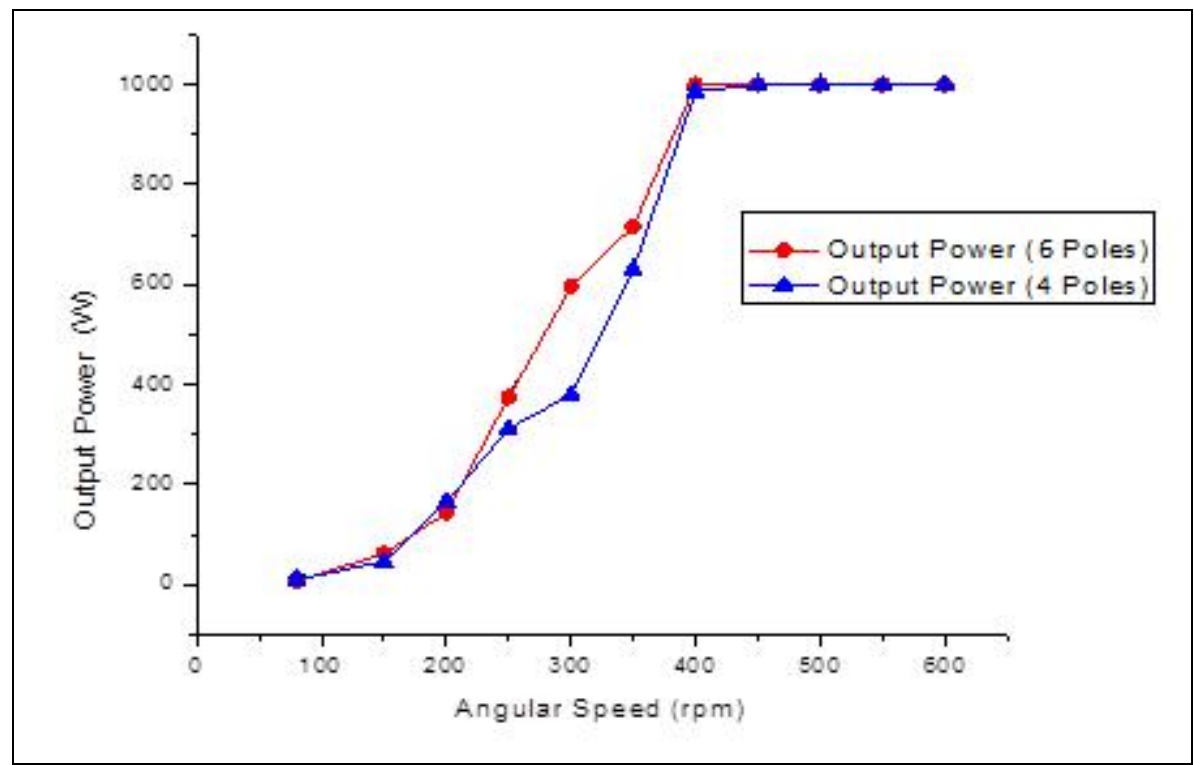

Figure 10: The comparison of power output of 6 and 4 pole pairs PMG

\section{CONCLUSIONS}

From the study in general it can be concluded that the best generator to be adopted for small scale wind energy harvesting is the PM AC generator designed with 6 pole pairs. At $50 \mathrm{rpm}$, the efficiency of 4 pole pair machine was $76.4 \%$ while the 6 poles machine was $77.4 \%$ and at the $650 \mathrm{rpm}$ the efficiency of 4 pole pars machine was $92.0 \%$ while the 6 pole pairs generator was $93.3 \%$. With these values we can conclude that the 6 poles machine is better than the 4 poles machine. The 6 poles generator has a good power output with less Total Harmonic Distortion (THD) and high efficiency of over $92.0 \%$ that can be achieved at low wind speed of $2 \mathrm{~m} / \mathrm{s}$.

\section{REFERENCES}

Abeywardena H., Atputharajah A. and Ekanayake J. (2011). Novel Technique to Smooth Power Output of a Wound Rotor Induction Generator Based Wind Turbine, $6^{\text {th }}$ International Conference on Industrial and Information Systems, ICIIS, Peradeniya, Sri Lanka, 517521.
Aleksander K. and Oleg K. (2012). Study and Verification of a Slow Speed PM Generator with Outer Rotor for Small Scale Wind Turbines. In Proceedings of Electric Power Quality and Supply Reliability Conference (PQ), Tartu, Estonia, 1-6.

Amirat, Y., Benbouzid, M., Bensaker, B. and Wamkeue, R. (2007). The State of the Art of Generators for Wind Energy Conversion Systems, Electromotion, Mediamira Science Publisher, 14(4): 163-172.

Ansoft Maxwell Field Simulator v12 (2008). Ansoft Electrical Machine Design Reference, Revision, June 2008.

Cao J., Yang X. and Zhu W. (2010). Design and Airgap Flux Density Calculation of Dual-Rotor Permanent-Magnet Wind Generator. Power and Energy Engineering Conference (APPEEC), Asia-Pacific, 1-4.

Cistelecan M., Ferreira F. and Popescu M. (2010). Adjustable Flux Three Phase AC Machines with Combined Multiple-Step Star-Delta Winding Connections. IEEE Transactions on Energy Conversions, 25(2): 348- 
355.

Chapadel P., Bikdash M., Kateeb I. and Kelkar A. (2011). Reactive Power Management and Voltage Control Of Large Transmission System Using SVC (Static VAR Compensator). Proceedings of the IEEE Southeastcon Conference, Nashville, Tennessee, USA, 85-90.

Dong-Choon L. and Ahmed G. (2008). Optimal Efficiency Control of Induction Generators in Wind Energy Conversion Systems using Support Vector Regression. Journal of Power Electronics, 8(4): 345353.

Dosiek L. and Pillay P. (2007). Cogging Torque Reduction in Permanent Magnet Machines. IEEE Transactions on Industry Applications, 43(6): 1565-1571.

Guo Y., Dou Y., Zhu J., Lu and Jin J. (2008). Numerical Magnetic Field Analysis and Computation of a PM Synchronous Generator. International Conference on Electrical Machines and Systems. ICEMS, Wuhan, China, 2866-2869.

Kolar J., Friedli T., Krismer F., Looser A., Schweizer M, Steimer P. and Bevirt J. (2013). Conceptualization and Multi-Objective Optimization of the Electric System of an Airborne Wind Turbine, IEEE Journal of Emerging and Selected
Topics in Power Electronics, 1(2): 73-103.

Ocak C., Uygun D., Cetinceviz Y., Demir E. and Gungor Y. (2012). Performance Aspects and Verifications of In-Runner and OutRunner Permanent Magnet Synchronous Generator Designs of the Same Magnet Structure for Low Speed Wind Systems. IEEE International Conference on Environment and Electrical Engineering, Turkey, 1-6.

Sittisrijan N. and Ruangsinchaiwanich S. (2013). Synthesis of Stator Current Waveform of Induction Motor with Broken Bar Conditions, International Conference on Electrical Machines and Systems (ICEMS), Busan, Korea, 34413445 .

Tamura J. and Muyeen S. (2012). Wind Energy Conversion Systems, Green Energy and Technology. SpringerVerlag, London, UK.

Tcheslavski G. (2008). Fundamentals of Power Engineering. Larmar University, Texas, USA.

Zhang L., Sun Y. and Lv X. (2011). Design on Pitch-control Wind Turbine System Based on Bladed. Proceedings of the IEEE Conference, Mianyang, China, 3921-3923. 